\title{
Responsabilidade Penal do Médico nos Casos de Transfusão de Sangue, em Menor de Idade, em Iminente Risco de Vida, cujos Pais são Adeptos da Setta Testemunhas de Jeová
}

CRIMINAL RESPONSIBILITY OF THE DOCTOR IN CASES OF BLOOD TRANSFUSION, IN MINOR OF AGE, IMMINENT RISK OF LIFE, WHO PARENTS ARE JEOVAH'S WITNESS

\author{
Jadir de Mattos ${ }^{(*)}$ \\ Kátia Rejane Stürmer ${ }^{(\star \star)}$ \\ Joselaine da Costa ${ }^{(\star \star \star)}$
}

\section{RESUMO}

O presente artigo tem por objetivo analisar os procedimentos médicos, que incluam a transfusão de sangue em seguidores da crença Testemunha de Jeová, menores de idade e que necessitem da autorização dos pais ou responsável legal. A análise abrange aspectos de direito à vida e à dignidade da pessoa humana, o direito de liberdade religiosa e a sua livre manifestação, a aparente colisão de direitos fundamentais. São analisados aspectos de religião, de ética médica e do Direito, com destaque para os princípios da razoabilidade e proporcionalidade, na busca de aplicar a técnica da ponderação de valores na colisão dos direitos fundamentais e valorizar o princípio da dignidade da pessoa humana como valor preponderante.

\section{Palavras-chave \\ Ética Médica; Transfusão de Sangue; Omissão de Socorro; Constran- gimento llegal; Responsabilidade Penal do Médico.}

(") Médico pediatra e anestesista do Hospital São Lucas, na cidade de Cascavel - PR. E-mail: <assessoriajadir@yahoo.com.br>.

("*) Advogada e Professora da Faculdade de Ciências Sociais Aplicadas de Cascavel. E-mail: $<$ <atia.sturmer@terra.com.br>.

("**) Advogada Especialista em Direito Penal pela Faculdade de Ciências Sociais Aplicadas de Cascavel. E-mail:<joselainejc@hotmail.com>. 


\section{ABSTRACT}

The present article has for objective to analyze the medical procedures including blood's transfusion in followers of the belief Witnesses of Jehovah, age minors that need the authorization of the parents or criminal liability. The analysis encloses aspects such as right to the life and the dignity of the human being, right of religious freedom and its demonstration and the apparent shock with the basic rights and ethic medical. This analyze is based in principles of the reasonability and proportionality searching to apply the technique of the balance of values referring to the collision of the basic rights and to enhance the main value which is the principle of the dignity of the human being.

\section{Key Words}

Medical Ethics; Blood Transfusion; Aid Omission; Illegal Embarrassy; Criminal Liability.

\section{INTRODUÇÃO}

O presente artigo tem a finalidade de analisar a responsabilidade penal do médico nos casos de transfusão de sangue não autorizada em menores, dependentes ou filhos de seguidores da crença religiosa das Testemunhas de Jeová. A importância do tema encontra amplitude na medida em que esclarece a opinião pública, a sociedade, a comunidade médica e os seguidores de tal religião.

Da análise das legislações procura-se destacar as medidas que poderão ser adotadas pelos médicos, discutindo a questão da responsabilidade penal (art. 146, $\S 3^{\circ}$ e art. 135, ambos do Código Penal) e médica (art. 46 do Código de Ética), evidenciando também os casos concretos de exclusão da ilicitude, previstos no art. 23, inciso III do Código Penal.

\section{TESTEMUNHAS DE JEOVÁ E TRANSFUSÃO DE SANGUE}

A seita cristã Testemunha de Jeová foi fundada em 1870, por Charles Russel, em Pittsburgh (Pensilvânia - EUA). Segundo Nilton Bezerra'1), "(...)

(1) VALE, Nilton Bezerra do; TSA, José Delfino. As nove premissas anestesiológicas da Bíblia. Revista Brasileira de Anestesiologia, v. 53, n. 1, p. 130, 2003. 
os seguidores não aceitam a transfusão sangüínea baseados em trechos do Antigo Testamento, interpretando a transfusão como similar ao ato de comer sangue" .

Os adeptos dessa seita, baseados na interpretação bíblica, fundamentados nos livros da Bíblia cristã - Genêsis 9:3.4(2), Levíticos 7.27; 17.:10(3) e Deuteronômio 12.25-28 - não admitem que ninguém de sua família se submeta a transfusão de sangue em intervenções cirúrgicas ou para salvar a vida de alguém em circunstâncias especiais.

A crença das Testemunhas de Jeová, por séculos, tem sido a de que Deus Jeová, o criador dos céus e terra, e de todo o ser vivente, tem um propósito para a vida de todos nós. O fundamento de tal alegação encontrase no livro de Provérbios 16.24 da Bíblia cristã e é com esta convicção que os fiéis mantêm sua esperança de vida apenas no criador de todas as coisas: Deus $^{(4)}$.

Biblicamente, o sangue é mais que um complexo líquido biológico que o menciona mais de 400 vezes, sendo que algumas dessas referências envolvem a salvação de vidas, como a que Deus declara que tudo aquilo que é vivo poderá servir de comida e que o homem deve comer da carne com vida, ou seja, com sangue. O sangue humano tem grande significado e não deve ser mal-empregado. O Criador acrescenta pormenores, por meio dos quais podemos facilmente depreender as questões morais a ele vinculadas.

Conforme a norma descrita no livro de Deuteronômio 12.23, o Criador ordenou aos homens que derramassem o sangue na terra como se fosse água. Diferentemente das idéias hoje defendidas de que a lei Divina sobre o sangue não deveria ser considerada em situação de emergência, embora naquele tempo, o uso medicinal do sangue não existisse, por mais ou menos dois mil anos, o sangue era utilizado como remédio para lepra e, em Roma, como tratamento contra epilepsia. Mas, aqueles que eram cristãos, já naquele tempo, entendiam que não podiam aceitar tal tratamento para curar suas doenças. As Testemunhas de Jeová dão à vida um valor muito alto em relação ao respeito às leis de Deus e por isso não aceitam este tipo de tratamento.

\section{CONSENTIMENTO X TRATAMENTO AUTORITÁRIO}

Mesmo sendo a liberdade um bem juridicamente protegido, não pode ela ser tolerada de forma irresponsável e contra o interesse comum. Quando

(2) "Todo animal movente que está vivo pode servir-vos de alimento. Como no caso da vegetação verde, deveras vos dou tudo. Somente a carne com sua alma - seu sangue - não deveis comer."

(3) "Quanto qualquer homem da casa de Israel ou algum residente forasteiro que reside no vosso meio, que comer qualquer espécie de sangue, eu certamente porei minha face contra a alma que comer o sangue, e deveras o deceparei dentre seu povo."

(4) MENEZES, Aldo. As testemunhas de Jeová e a Bíblia. São Paulo: Vida, 2003. p. 6. 
essa liberdade é inconseqüente, passa a conflitar-se com a liberdade das outras pessoas ou com as exigências de uma ordem pública e de um bem social. A liberdade existe para fazer do indivíduo um ser harmônico. Estando ela fora dessas considerações, torna-se um abuso(5).

O que o Estado protege não é a liberdade natural de o homem fazer ou deixar de fazer o que não quer, mas, a liberdade social, a qual assegura a qualquer um de nós o exercício da própria vontade, dentro de um limite permitido pela norma regulamentadora. Em suma, o que se tutela é a liberdade responsável.

Deste modo, a legislação brasileira exclui em duas situações a antijuridicidade do constrangimento ilegal: no tratamento médico arbitrário diante do iminente perigo de vida e no impedimento ao suicídio, de acordo com o art. 146, incisos I e II do Código Penal.

Uma enfermidade, mesmo grave, mas sem perigo imediato ou risco remoto de morte não justifica tal intervenção médica. $O$ elemento que caracteriza a exclusão da sanção penal é o estado de necessidade de terceiro, que a doutrina moderna aceitou, dirimindo dúvidas e afastando as controvérsias. Sacrifica-se um bem - a liberdade, para salvar um outro, de maior interesse e significação que é a vida, da qual ninguém pode dispor incondicionalmente, pois a reclama outro titular de direito - a sociedade, para a qual o indivíduo não é apenas uma unidade demográfica, mas, sobretudo um imensurável valor social e político(6).

A autonomia do paciente é a extensão da eqüidade onde associa-se a idéia de respeito pelo próximo. É tratando com respeito o paciente em sua condição humana que o médico poderá obter o consentimento para que realize sua função, a qual está repleta de riscos, e compreender as razões de certas terapêuticas não serem aceitas e viáveis e, a partir daí, procurar outras alternativas para curá-lo ou amenizar o seu sofrimento. O médico deve manter o sigilo que a sua profissão pede, uma vez que terá acesso a informações que poderá acarretar em constrangimento se forem reveladas. O respeito à vida é um dos maiores princípios da ética médica, tendo de se moldar às condições sociais vividas.

É imperativo que o médico entenda que nos casos de não emergência, deve ele ter o consentimento expresso ou tácito do seu paciente ou familiares, pois aí está prevalecendo apenas interesse de ordem pessoal. Assim, para o tratamento compulsório é preciso não apenas a existência de perigo de vida, mas também que essa intervenção seja urgente, necessária e inadiável, numa iminência de morte, para justificar tal conduta.

(5) DORSA, Paschoal José. O direito à vida e à liberdade de crença. Testemunhas de Jeová. Transfusão de sangue. Assinatura de termo de responsabilidade e autorização. Recusa. Procedimento Médico e Administrativo, em face da Constituição. Revista dos Tribunais, São Paulo, v. 84, n. 714, p. 98-103, 1995.

(6) ld. Ibid. 
De outro ponto de vista, a expressão "arbitrária" é imprópria, tendo em vista que o médico não faz outra coisa senão o que sua ciência permite, como condição obrigatória, e o que sua consciência determina pelo conteúdo histórico de sua profissão. A arbitrariedade não estaria no tratamento, mas, na forma de contorná-lo em face da recusa do paciente. Tratamento arbitrário, stricto sensu, seria realizar uma conduta terapêutica de caráter experimental em alguém contra sua vontade, quando o tratamento convencional o curaria(7).

Deve-se entender como perigo de vida a situação em que existe uma possibilidade concreta de êxito letal e que exige uma atuação rápida, decisiva e inadiável, a fim de evitar a morte. A emergência e a urgência médicas são situações de fácil entendimento para o profissional da Medicina, não sendo necessário muito apuro e muitos recursos para delimitá-las plenamente.

Fora destas considerações, há um tema muito delicado para se tratar quando se fala do internamento e tratamento psiquiátrico involuntários, notadamente quando eles ocorrem sem o consentimento do paciente ou de seus responsáveis legais. Mesmo que se fale de uma cura improvável, de uma suposta periculosidade e de uma falta de discernimento do paciente, ainda assim, sob o ponto de vista moral, não se pode dizer que este paciente perdeu de todo sua autonomia e seus direitos de cidadania. Sendo assim, a utilização da "força bruta", de substâncias químicas ou de qualquer outro meio para diminuir a resistência ao tratamento indesejado, são procedimentos no mínimo ultrajantes e ofensivos ${ }^{(8)}$.

Só se pode admitir esta forma de tratamento e de internamento quando se caracterizar um perigo real para o paciente ou para outrem. $E$ mais: no momento em que o paciente sai deste estado, deve ser imediatamente considerado um paciente voluntário, e a sua autonomia deve ser reintegrada e respeitada.

Nas outras formas de atendimento médico, quando o profissional estiver diante de um caso de recusa de condutas terapêuticas ou práticas diagnósticas, o ideal será um acordo eticamente defensável entre ele, o paciente e/ou a família até se chegar a uma solução em que o assistido seja favorecido. O mais difícil nesta questão é quando o paciente ou seus responsáveis não aceitam ou não admitem continuar com o tratamento ou fazer os exames necessários, por considerá-los fúteis ou imprestáveis, diante de alguns estados considerados incuráveis. Em tais ocorrências, o médico deve esgotar

(7) GILLON, Raanan. Refusal of potentially life-saving blood transfusions by Jehovah's witnesses: should doctor explain that not all JWs thinks it's religiously required? Journal of Medical Ethics, v. 26, P. 299-301, 2000.

(8) FRANÇA, Genival Veloso. Comentários ao Código de Ética Médica. 3. ed. Rio de Janeiro: Guanabara Koogan, 2000.p. 69. 
todos os meios para conquistar a adesão deles, só podendo intervir quando a lei e o seu código permitirem: diante do iminente perigo de vida (princípio da beneficência) ${ }^{(9)}$.

No caso das Testemunhas de Jeová, há uma corrente que afirma ser a liberdade o primeiro direito na hierarquia dos direitos fundamentais do indivíduo e chega mesmo a enfatizar que entre o direito à vida e o direito à liberdade, a escolha é do titular desse privilégio, atendendo-se ao princípio da autonomia. Desta forma, teria o paciente o direito de aceitar ou não um tratamento por imperativo religioso, mesmo que ele fosse o único meio de salvar-Ihe a vida, pois isto estaria constitucionalmente consagrado na Carta Magna (incisos $\mathrm{VI}$ e $\mathrm{X}$ do art. $5^{\circ}$ ), em respeito à liberdade de consciência e de crença.

Afirma-se ainda que o dever do médico é de fonte legal e o direito do paciente de aceitar ou recusar um tratamento é "expressão de sua liberdade", segundo a Constituição brasileira em vigor. O médico cumpriria suas obrigações apenas informando ao paciente ou ao seu responsável legal da necessidade ou da conveniência de uma conduta ou de um tratamento e de suas conseqüências advindas pela não aceitação, mesmo que seu Código de Ética, em seus arts. 46, 47 e 56, se expresse claramente dizendo que "é vedado ao médico efetuar qualquer procedimento sem o esclarecimento e o consentimento prévios do paciente ou de seu responsável legal, salvo em iminente perigo de vida".

Insiste-se dizendo que a interpretação literal deste dispositivo do Código de Ética Médica é absurda, pois pelo fato de o paciente estar diante de um perigo de vida ele não perdeu o direito fundamental à liberdade, seja no aspecto religioso, seja no aspecto de sua privacidade.

Há ainda a afirmação de que no atendimento médico no caso da recusa do paciente não existe crime porque isto se deu por manifestação tácita ou expressa do assistido ou de seus responsáveis legais. Houve, apenas, segundo aqueles defensores desta idéia, uma recusa de tratamento por parte do paciente.

Mesmo no caso de crianças, reconhecem que os pais ou representantes gozam do direito de aceitarem ou não determinada forma de assistência médica destinada a elas. $E$ quando o menor for capaz de demonstrar maturidade para decidir, afirmam, pode também recusar o tratamento.

Deve o médico entender, no que se refere às Testemunhas de Jeová, que em muitas ocasiōes o sangue pode ser substituído por outros fluídos ou não ser usado e, por isso, poderá desenvolver uma forma de tratamento que não sacrifique a vida nem comprometa seus princípios religiosos. Não

(9) WADE, Paul. Treatment of patients who are jehovas witnesses. Joumal of Medical Ethics, v. 27, p. 137 $138,2001$. 
esquecer também que esses adeptos não abriram mão da vida e não desacreditam na medicina, mas apenas face a sua conviç̧ão religiosa solicitam abster-se de sangue.

Infelizmente nem sempre é possível tal conciliação. A legislação penal substantiva em vigor admite como crime deixar de prestar assistência às pessoas em grave e iminente perigo de morte (art. 135) e exclui da categoria de delito a intervenção médica ou cirúrgica, mesmo sem consentimento do paciente ou de seu responsável legal, se justificada por iminente perigo de vida (art. 146). Neste caso, o médico deve agir porque está amparado no exercício regular de seus direitos e no cumprimento do dever legal, de acordo com o art. 23, III do dispositivo penal.

\section{CRENÇA RELIGIOSA X ÉTICA MÉDICA}

Os profissionais da área médica enfrentam muitos casos de transfusão de sangue em pacientes que são seguidores da crença Testemunha de Jeová, não apenas no Brasil, como em diversos países ${ }^{(10)}$.

O Código de Ética Médica é um complemento e praticamente é ele que direciona e limita as atividades médicas sobre sua aplicação (medicina) para que não se perca os valores humanos, conduzindo a um bom relacionamento entre médico/paciente, médico/médico e médico/sociedade. Os códigos e leis específicos têm o condão de balizar as atividades do homem/ médico, flagrando deslizes nesta profissão que acabam passando despercebidos pelos Conselhos de Ética Médica.

Com o desenvolvimento material em relação às técnicas hoje empreGgádas pela Medicina, faz-se necessário averiguar mais ainda as atividades do médico para que cumpram com suas funções e contribuam para a assistência da saúde com primazia atendendo a sua função social. No principio bioético de não prejudicar (primum, non nocere), explica Fernando Monte(11), "entrecruzam-se os conceitos de utilidade, benefício, risco e dispêndio".

A Convenção Européia para a Proteção dos Direitos do Homem e da Dignidade do Ser Humano prevê, no art. 5ํ, a necessidade de consentimento livre e esclarecido de qualquer intervenção no domínio da saúde. No art. 8 prevê que, em casos de urgência, quando não for possível colher o consentimento, poderão ser feitas todas as intervenções médicas necessárias para garantir a saúde do paciente.

(10) FIALHO, Carla Cabogrosso. Transfusão de sangue e Testemunhas de Jeová - autonomia x Ética Médica. Revista do Instituto de Pesquisa e Estudos, Bauru, v. 36, p. 65, 2003.

(11) MONTE, Fernando Q. A ética na prática médica. Disponivel em: <http//www.portalmedico.org.br/ revista/bio10v2/artigo2.htm>. Acesso em: 10.out.2005. 
Porém, tais posiçōes podem gerar conflitos entre a consciência do paciente Testemunha de Jeová e o dever do médico, que se ampara no art. $56^{(12)}$ do Código de Ética Médica para desrespeitar a decisão tomada por seu paciente no que atine a atos que devem ser praticados, em que o mesmo se encontra em iminente perigo de vida.

Tal consentimento é caracterizado como uma decisão e um ato, sem restrições internas e externas, esclarecido com as informações necessárias à situação. $O$ assunto está na pauta das discussões sobre ética médica na atualidade. O propósito de se requerer este consentimento é promover a autonomia do indivíduo na tomada de decisões com relação a assuntos de saúde e tratamento médico. Para o consentimento ser uma autorização válida, ele deve ser baseado na compreensão e na voluntariedade.

\section{RISCOS DA TRANSFUSÃO DE SANGUE}

Graças às melhores técnicas de triagem do sangue, as transfusões atualmente são mais seguras do que nunca. No entanto, elas ainda apresentam riscos para o receptor (tais como alergias e infecçōes). Apesar da chance de infecção pelo vírus da AIDS ou da hepatite por transfusão serem remotas, os médicos estão bem conscientes desse risco e somente a prescrevem quando não existe alternativa diversa.

Como a transfusão sangüínea pode trazer uma doença infecciosa presente no sangue do doador, as autoridades sanitárias são rigorosas na seleção de doação de sangue, fazendo com que os exames feitos pelos doadores sejam mais abrangentes. Atualmente, todas as doaçōes de sangue são testadas para as hepatites virais, a AIDS, a sífilis e outros vírus selecionados.

Em contraposição, Finucane observa que o fato das pessoas considerarem a transfusão de células perigosa, pelo risco de contraírem doenças tais como a AIDS é um estigma evidentemente negativo, gerado pela má informação, criando assim, a polêmica acerca da transfusão. O mesmo autor conclui seu artigo expondo que o melhor a ser feito nessa ocasião é diminuir as dúvidas do paciente, aumentando assim, a sua confiança a respeito deste tipo de tratamento, diminuindo os riscos de vida, evitando-se assim, conseqüências catastróficas ${ }^{(13)}$.

Diversas dessas doenças possuem tratamento, mas muitas delas não têm cura, obrigando a pessoa a conviver com tal doença durante toda a sua

(12) Art. 56 do Código de Ética Médica: “É vedado ao médico: desrespeitar o direito do paciente de decidir livremente sobre a execução de práticas diagnósticas ou terapêuticas, salvo em caso de iminente perigo de vida."

(13) FINUCANE, M. L.; SLOVIC, P.; MERTIZ, C. K. Public perception of the risk of blood transfusion. United States. Transfusion, v. 40, Aug. 2000. p. 1017. 
vida. No caso da doença da vaca louca, como ficou conhecida, era provocada por células e plasma infectados por tal vírus, o que ocasionara a destruição do tecido cerebral.

\section{ALTERNATIVAS À TRANSFUSÃO DE SANGUE}

Aqui serão discorridas as alternativas à transfusão de sangue, lembrando-se, no entanto, que o objeto do artigo trata de crianças menores de idade, em iminente perigo de vida, vítimas de acidentes gravíssimos, sendo a sua única alternativa de sobrevivência este tipo de tratamento.

O objetivo da transfusão de sangue é a de suprir a perda sangüínea em acidentes em casos de hemofilia e leucemia. A transfusão é prescrita pelo médico e, antes desse procedimento ser executado, devem ser realizados diversos testes de compatibilidade. A transfusão é em geral de sangue total ou papas de hemácias.

A transfusão é feita com a finalidade de aumentar a capacidade do transporte de oxigênio, restaurar o volume sangüíneo, melhorar a imunidade e corrigir os distúrbios de coagulação. A transfusão pode ser total ou parcial. Parcial é quando recebe hemocomponentes selecionados ${ }^{(14)}$.

É sabido que já existem novas maneiras de fazer cirurgias sem a transfusão de sangue, o que é muito defendido pelos adeptos desta religião. A professora Tereza Rodrigues Vieira reza que "os médicos que fazem uso destas terapias estão cientes da obrigação da utilização de técnicas de conservação de sangue com o intuito de minimizar a perda do sangue, tornando desnecessária a sua reposição"(15).

A terapia transfusional de componentes refere-se à transfusão de parte específica do sangue que o paciente necessita, opondo-se ao uso mais comum que é de sangue total. Esta forma de terapia médica não apenas conserva os estoques de sangue, mas também, permite que seja transfundida maior quantidade de um determinado componente que o paciente necessite.

Mesmo que o risco tenha diminuído como já se havia falado, pela melhora na triagem de doadores e dos testes laboratoriais, a grande preocupação ainda é a transmissão de microrganismos patogênicos, como bactérias, protozoários e vírus ${ }^{(16)}$ que não podem ser detectados por simples testes e outros para os quais os testes ainda nem sequer existem.

(14) FINUCANE, M. L.; SLOVIC, P.; MERTIZ, C. K. op. cit. p. 1018.

(15) VIEIRA, Tereza Rodrigues. Reflexões bioéticas na recusa de transfusão de sangue em testemunhas de Jeová. Revista Consulex, Brasília, ano 8, n. 182, 15.ago.2004. p. 265.

(16) Ainda tem-se o HIV cuja transmissão através da transfusão de sangue não pode ser antecipada e deveria servir para que os cientistas e profissionais da área continuassem com as mudanças na área hematológica, garantindo uma segurança sangüínea. 
Por isso, os profissionais da área estão se esforçando para que outras formas de terapias sejam utilizadas por todos os hospitais, buscando assim, maior resultado positivo e tornando zero o índice de transmissōes virais pelo tratamento.

As Testemunhas de Jeová hoje em todo o mundo se submetem a outros tratamentos que alcançam o mesmo resultado da transfusão sangüínea atingindo até mesmo uma recuperação mais rápida do que na terapia padrão.

Mesmo que a ciência tenha evoluído não apenas nos aspectos científicos, como também com relação à compreensão do ser humano, infelizmente uma grande maioria ainda possui o antiquado preconceito. A Constituição e as Convenções Internacionais reconhecem o tema religião como algo que não se discute: cada cidadão deve ter a sua fé e crenças respeitadas, sendo essa uma das condições do ser humano - a liberdade de crença/religião/ consciência.

Durante toda a história das Testemunhas de Jeová, elas mantiveramse firmes em recusar o método terapêutico transfusional, devido conflitar com sua lealdade a Deus. Por essa razão, diante de outros fatores como doenças infecciosas e doenças parasitárias, a Medicina e a Ciência têm procurado outras formas para substituir a transfusão de sangue.

A Carta Magna garante indiscutivelmente a liberdade de consciência; mas, legislações específicas excetuam este direito em caso de perigo iminente, principalmente no que tange a menores impúberes; com este exceto os médicos infringem o direito do ser humano de ter sua crença e seu direito de escolha respeitados.

\section{LIBERDADE DE CONSCIENCIA X DIREITO A VIDA}

Os direitos fundamentais são direitos que decorrem da própria natureza do homem, não sendo, portanto, "uma criação legislativa, mas uma criaçâo de todo um contexto histórico cultural da sociedade"(17).

O direito fundamental à liberdade engloba liberdades determinadas, sendo uma delas a religiosa que, segundo José Afonso da Silva, inclui-se entre as liberdades espirituais; porém, seu conteúdo é mais complicado pelas implicações que suscita, compreendendo três formas de expressão: a) liberdade de crença; b) a liberdade de culto; e c) liberdade de organização religiosa, todas previstas pela Constituição(18).

(17) VIEIRA, Tereza Rodrigues. op. cit.

(18) SILVA, José Afonso da. Curso de direito constitucional positivo. 15. ed. São Paulo: Malheiros Ed., 1998. p. 251. 
As liberdades religiosas de consciência tornaram-se direitos fundamentais de Direitos Humanos após a Segunda Grande Guerra e foram garantidas também na Convenção Internacional sobre Diretos Civis e Políticos, nos acordos de Helsinque, na Convenção Européia de Proteção de Direitos Humanos e das Liberdades Fundamentais e nas Declarações das Nações Unidas.

Atualmente, o Brasil é um país laico, sem nenhuma religião oficial. Diferente do que já foi um dia quando a Constituição de 1824 adotou a religião Católica Apostólica Romana como a única religião oficial. Segundo o professor Luiz Vicente Cernicchiaro, o disposto no art. 5, incisos VI e VII são conseqüência disto(19). Complementando com o pensamento do professor Alexandre de Moraes, "a constituição, ao consagrar a inviolabilidade de crença religiosa, está também assegurando plena proteção à liberdade de culto e a suas liturgias"(20).

A cada dia aumentam os casos em que pessoas perdem suas vidas de forma inútil, recusando-se a receber transfusōes de sangue por pertencerem à determinada seita religiosa que proíbe esse tipo de terapêutica.

Deve-se primeiramente analisar a liberdade religiosa, assegurada pela Constituição Federal, em seu art. 5ํ, VI, que diz: "é inviolável a liberdade de consciência e de crença, sendo assegurado o livre exercício dos cultos religiosos", sendo que é pressuposto de todo o direito a ser utilizado de forma a não prejudicar igualmente o direito de outrem. Nesta mesma linha de raciocínio, o art. 5ㅇ, VIII da Magna Carta assegura que ninguém será privado de direitos por motivos de crença religiosa ou de conviç̧ão filosófica ou política. Ainda, em seu art. 5ํ. X, está expressa a inviolabilidade da intimidade, da vida privada, da honra e imagem das pessoas. São direitos autônomos entre si, sendo que a proteção de cada um não depende da violação do outro. Neste sentido, a liberdade de crença está incursa no campo dos direitos e garantias fundamentais, que tem como finalidade primordial o respeito à dignidade da pessoa humana, garantindo condições de vida e desenvolvimento de sua personalidade(21).

Através do Decreto Legislativo n. 27, de 26 de maio de 1992, foi aprovado o texto da Convenção Americana de Direitos Humanos, conhecido como o Pacto de São José da Costa Rica, sendo que, em 25 de setembro de 1992, o Governo Brasileiro depositou a Carta de Adesão a essa Convenção e, pela manifestação de vontade do povo acolhida pelo Congresso Nacional e pelo Poder Executivo, este pacto passou a integrar nosso ordenamento jurídico como Lei Ordinária Federal, estabelecendo no seu princípio XVII que "Todo homem tem direito à liberdade de pensamento, consciência e religião;

(19) CHERNICCHIARO, Luiz Vicente. Transfusão de sangue. Revista Jurídica, n. 262, p. 53, ago.1999. (20) MORAES, Alexandre de. Direito constitucional. 12. ed. São Paulo: Atlas, 2002. p. 73.

(21) FIALHO, Carla Cabogrosso. op. cit., p. 66. 
este direito inclui a liberdade de manifestar essa religião ou crença, pelo ensino, pela prática, pelo culto e pela observância, isolada em público ou em particular".

Além de ser uma premissa constitucional, a não discriminação da religião é prevista também no Código de Ética, em seu art. 56, o qual apregoa que é vedado ao médico desrespeitar o direito do paciente de decidir livremente sobre a execução de práticas diagnósticas ou terapêuticas, salvo em caso de iminente perigo de vida.

A professora Tereza Vieira preconiza que tal artigo fere frontalmente os direitos fundamentais previstos na Constituição, sendo nula e de nenhum valor legal. Conclui ressaltando que: "a escolha, a opção por esta ou aquela religião merece a tutela do Estado não podendo intervir ou coagi-la a fazer ou deixar de fazer o que a lei não dispōe, sobretudo quando se trata de matéria ligada à autonomia do indivíduo."(22)

Conforme uma determinada convicção ética, a vida humana, a vida de cada indivíduo isolado, é o valor maior. A partir desta concepção, tornou-se absolutamente proibido matar um ser humano, seja na guerra ou com a pena de morte, assim sendo, aquele que matar, absorverá as penalidades a ele impostas pela legislação.

Esta concepção é reconhecida pelos refratários ao serviço militar e daqueles que são, por princípio, contra a pena de morte. Mesmo assim, também existe a concepção contrária, de acordo com a qual o interesse e a forma da nação prevalecem sobre esta. Com isso, cada um tem o dever ético de sacrificar sua própria vida para matar outros, na guerra.

Em última análise, é o sentimento, o elemento emocional, e não o racional da atividade consciente que soluciona o conflito.

O direito à vida, tal como o direito à liberdade de consciência está previsto na Carta Magna como um direito fundamental, sendo como visto anteriormente, histórico, imprescritível, inalienável e irrenunciável ${ }^{(23)}$. Deve ser entendido então como direito da pessoa humana a uma vida com dignidade ${ }^{(24)}$.

Hodiernamente, o direito à vida não é apenas interesse do indivíduo, mas também do Estado, que tem o interesse de preservá-la, assumindo a posiçāo de garantidor de tal bem jurídico. Segundo Ana Carolina Paes Leme, "justifica-se a intervenção estatal no sentido de tutelar, salvaguardar e proteger a vida por entendê-la como premissa básica para o exercício de qualquer outro direito fundamental"(25).

(22) VIEIRA, Tereza Rodrigues. op. cit., p. 268.

(23) SILVA, José Afonso da. op. cit., p. 185.

(24) LEME, Ana Carolina Reis Paes. Transfusão de sangue em testemunhas de Jeová: a colisão de direitos fundamentais. Disponivel em: <http//jus2.com.br/doutrina/texto.asp?id=6545.> Acesso em: 8 . out.2005.

(25) Id. Ibid. 
O ordenamento jurídico traz que a vida é um bem jurídico inviolável, não podendo ser violada por terceiros, mas também não permite a sua disponibilidade, por reconhecer a supremacia da dignidade humana como fundamento principal, entendendo que a vida é um pressuposto para que outros direitos fundamentais sejam manifestados.

Luiz Vicente Cernicchiaro declara que o bem da vida não é passível de disposição quando diz:

"O direito penal brasileiro volta-se para um quadro valorativo. Nesse contexto, oferece particular importância à vida (bem jurídico). Daí ser indisponível (o homem não pode dispor da vida). A irrelevância penal do suicídio decorre de política criminal, a fim de a pessoa que tentou contra a própria vida seja estimulada a mudar de idéia, o que provocaria efeito contrário se instaurado inquérito policial, processo, e depois, condenação, cumprimento de pena"(26).

Nesse diapasão, mesmo sendo o direito à vida revestido de relevância jurídica, este não tem caráter absoluto, sendo necessário considerar juntamente com outros direitos fundamentais, tendo em vista este não ser o único direito fundamental previsto na Constituição. Nesse âmbito, surge o princípio da dignidade da pessoa humana, que é o fundamento do nosso Estado de direito democrático e social, e segundo a professora Ana Carolina, tal direito tem "valor absoluto no sentido de balizar qualquer ingerência a outros direitos fundamentais"(27). Sendo assim, vê-se que nenhum direito é absoluto, tendo em vista que todos os direitos fundamentais encontram limites no princípio da dignidade da pessoa humana.

Existem alguns procedimentos indicados pelo Conselho Regional de Medicina para a equipe médica que se encontra no meio deste conflito. A regra geral é que o médico terá de analisar se o quadro clínico do doente apresenta ou não a necessidade de uma transfusão urgente. Em caso de não existir o caráter emergencial, o médico deve respeitar a vontade do paciente e de seus familiares e, nos casos em que não o faça (respeite a vontade do paciente), poderá ser penalizado de acordo com nossa legislação penal previsto no art. 146 por constrangimento ilegal.

Se ao invés disso, o paciente necessitar urgentemente de sangue para que tenha sua vida resguardada, deve o médico realizar o procedimento e buscar um alvará judicial de autorização para que a realização desse.

\section{RESPONSABILIDADE PENAL DO MÉDICO}

Em relação a pacientes menores de idade, a questão da transfusão de sangue é mais polêmica, tendo em vista que os pais querem ter a sua crença respeitada. Segunda Tereza Rodrigues Vieira:

(26) CERNICCHARO, Luiz Vicente. op. cit.

(27) LEME, Ana Carolina Reis Paes. op. cit. 
"Sustentam as Testemunhas de Jeová que a decisão do menor amadurecido deve ser respeitada, visto que já compreende as implicações advindas do seu ato, por ser oriundo de uma comunidade que respeita os seus ditames. (...) Data venia dos entendimentos em sentido contrário, o nosso entendimento é pela aceitação da recusa do menor conscientizado, devendo os casos relativos às crianças serem levados ao conhecimento do Judiciário objetivando dirimir o conflito. Os pais não podem dispor da vida dos filhos. Por vezes, ao atingirem a maioridade, estes vêm a professar outro credo, diverso daqueles dos pais. ${ }^{(28) "}$

De acordo com 0 art. $5^{9}$ do Código Civil, a menoridade cessa aos dezoito anos, momento em que a pessoa fica habilitada à prática de todos os atos da vida civil. Nesse sentido, cabe aos pais o direito de decidir por elas, até que finalmente, atinjam a maioridade. Segundo José Maria da Costa Orlando, "isto significa que a decisão de continuar ou parar com o auxílio médico é aquela que os pais estabelecem como sendo a mais justa, e tomada sempre em favor da criança"(29).

O Novo Código Civil antecipou a maioridade para os dezoito anos, reforçando ainda mais a questão de Manoel Gonçalves. Analisando o Estatuto da Criança e do Adolescente, em seu art. $15 \mathrm{c} / \mathrm{c}$. art. 16, II e III, os quais afirmam que a criança tem direito à liberdade de opinião, expressão, crença e culto religioso, demonstrando que, sempre que possível, em matéria de ordem médica, é necessário ouvir o menor, na medida da sua maturidade.

Nos dizeres de Valderez Bosso(30) "(...) ninguém pode ser constrangido a consultar um médico ou submeter-se a um tratamento terapêutico específico contra sua vontade livre e consciente manifestada". Em contrapartida, no que tange às crianças e adolescentes, primeiramente é preciso saber quais as conseqüências pela orientação adotada pelas pessoas responsáveis pelo menor de idade. E depois é preciso configurar a responsabilidade do profissional médico.

A família que recebe a proteção estatal não tem apenas direitos, mas possui também o dever de juntamente com a sociedade e o Estado, assegurar com absoluta prioridade, os direitos fundamentais da criança e do adolescente enumerados no art. 227 da Constituição Federal.

O Estatuto da Criança e do Adolescente dispõe em seu art. $1^{2}$ proteção integral à criança e ao adolescente. Segundo Celso Bastos, tal proteção baseia-se no reconhecimento de direitos especiais e específicos de toda criança e adolescente, reiterando o disposto no art. 227 da Constituição(31).

(28) VIEIRA, Tereza Rodrigues. op. cit., p. 274.

(29) ORLANDO, José Maria da Costa. Alguns aspectos ético-legais da prática do intensivismo. Disponivel em: <http/hwww.sopati.com.br/aspectoseticos.htm> Acesso em: 4 .jun.2005.

(30) BOSSO, Valderez; MENDES, Regiane A. Questóes constitucionais e legais referentes a tratamento médico sem transtusáo de sangue. Disponível em: <http/hwww.oabjundiai.org.br/artigos_19_05_2005.htm> Acesso em: 19.maio.2005.

(31) BASTOS, Celso Ribeiro. Curso de direito constitucional. 19. ed. São Paulo: Saraiva, 1998. p. 494. 


\section{PRINCÍPIOS DA PROPORCIONALIDADE E RAZOABILIDADE: DIREITOS FUNDAMENTAIS EM CONFLITO}

A colisão de direitos fundamentais dá-se a partir do seu exercício, havendo confronto entre si ou entre outros bens jurídicos protegidos pela Carta Ápice. Segundo Luciano Sampaio(32), antes de se falar em conflito aparente de normas, cabe uma observação:

"Considerando que não há hierarquia entre as diversas normas constitucionais e que o sistema jurídico é um todo harmônico, o conflito entre aquelas é apenas aparente. Assim, por exemplo, não há conflito, no plano normativo, entre as normas que garantem o direito à liberdade de imprensa e o direito à intimidade. Porém, no plano fático, a incidência delas sobre uma dada situação pode gerar uma colisão real entre os mencionados direitos constitucionais."

O tema da recusa à transfusão de sangue por parte das Testemunhas de Jeová implica em uma aparente colisão de tais direitos, pois envolve, de um lado, a vida e, de outro, a liberdade religiosa, ou seja, o direito do paciente de recusar tratamento por causa de convicções religiosas, sendo ambos os princípios regidos pela Constituição, não tendo o legislador estabelecido a cláusula de reserva. Nesse sentido, necessário se faz saber se há hierarquia entre os princípios constitucionais considerados em si mesmo.

Como existe mais de um princípio em conflito é impossível se faz usar a técnica da subsunção, pois não é dado ao intérprete o poder de optar por uma norma, desprezando a outra em tese aplicável, criando desta forma, certa hierarquia entre elas.

Luciano Sampaio ${ }^{(33)}$ qualifica esse conflito de direitos fundamentais entre o direito à vida e o direito à liberdade de crença como sendo um tipo de colisão excludente, "em que a realização concomitante dos direitos em colisão, conforme visto, é impossível, vez que o exercício de um deles exclui a do outro, incumbe perquirir qual direito fundamental expõe-se, no caso concreto, a um perigo de lesão mais grave". George Marmelstein de Lima(34) afirma que:

"Do ponto de vista jurídico é forçoso admitir que não há hierarquia entre os princípios constitucionais. Ou seja, todas as normas constitucionais têm igual dignidade; em outras palavras: não há normas constitucionais meramente formais, nem hierarquia de supra ou infra-ordenação dentro da Constituição."

(32) ROLIM, Luciano Sampaio Gomes. Colisão de direitos fundamentais e princípio da proporcionalidade. Disponivel em: <http//www.jus2.uol.com.br/doutrina/texto.asp?id=2855>. Acesso em: 8.ago.2005.

(33) Id. Ibid.

(34) LIMA, George Marmelstein. A hierarquia entre princípios e a colisão de normas constitucionais.

Disponivel em: <http//www.ambito-juridico.com.br/aj/dt>. Acesso em: 8.out.2005. 
Nesse sentido, os direitos fundamentais não devem se sobrepor, mas sim serem aplicados em conjunto, visando o preceito maior garantido pela Constituição, que é a dignidade da pessoa humana.

Valeschka e Silva Braga ${ }^{(35)}$ entende que a colisão dos princípios não se resolve pelo método do tudo ou nada, tendo em vista que os princípios colidentes devem ter seus pesos dimensionados, sendo eles igualmente valorados, prevalecendo no caso concreto aquele que tem maior polpa.

Isto posto, Ana Carolina Paes Leme(36) preconiza que "é imprescindível considerar a força do princípio da dignidade humana como valor preponderante, com vistas a guiar decisão final acerca da prevalência de um direito fundamental".

Uma das funções do princípio da proporcionalidade tem sido empregada no sentido de interpretação das normas constitucionais, incluindo-se neste rol a resolução de conflitos entre princípios.

Diante disto, o princípio da proporcionalidade é dotado de dupla dimensionabilidade, pois tanto limita como impõe a atuação estatal, garantindo a eficácia e observância deste, sendo, portanto, um princípio vinculante do intérprete do Direito, estando implícita na Constituição a sua obrigatoriedade. O princípio da proporcionalidade caminha junto com o princípio da razoabilidade, significando que a ponderação entre os meios empregados e os fins atingidos é a busca do razoável.

Os direitos fundamentais não são de maneira alguma absolutos, pois devem conviver harmonicamente, sendo passíveis de limitação (nunca de aniquilamento), diante de outro bem jurídico de igual valor. Nesse sentido, os princípios da proporcionalidade e da razoabilidade validam as escolhas do poder público, tendo em vista que tal princípio tem a função de regular condutas e estabelecer normas que sejam aceitas pela sociedade, mesmo que por receio de uma suposta sanção pelo seu não cumprimento.

Finalizando tal pensamento, Maria Christina de Almeida(37) cita que:

"Em caso de colisão de direitos fundamentais, a técnica correta para aferição da proporcionalidade em sentido estrito é a ponderação de bens, pela qual se estabelece uma relação de precedência condicionada, que vale como lei para determinado conflito. Esse procedimento é bastante útil para se aferir a compatibilidade de uma norma legal restritiva de direito ao princípio em exame não somente quando a

(35) BRAGA, Valeschka e Silva. Princípios da proporcionalidade \& da razoabilidade. Curitiba: Juruá, 2004. p. 34.

(36) LEME, Ana Carolina Reis Paes. op cit.

(37) ALMEIDA, Maria Christina de. Uma reflexão sobre o significado do princípio da proporcionalidade para os direitos fundamentais. Disponível em: <http//www.ufpr.br/direito/art/mariac2.htm> Acesso em: 8.out.2005. 
finalidade da lei foi a de limitar o âmbito de proteção de um direito, mas quando, a pretexto de regular determinada matéria, por via reflexa se a restrição a um outro direito."

A proporcionalidade, em sentido estrito, implica o máximo benefício com o mínimo sacrifício, sendo postos de um lado da balança os interesses protegidos com a medida, e do outro, os bens jurídicos que serão restringidos ou sacrificados por ela.

Neste diapasão, o correto domínio do princípio da proporcionalidade certamente terá o condão de tornar a vida do operador do direito bem mais fácil, conforme se pôde verificar através do presente estudo, onde foram analisadas, à luz da proporcionalidade, a validade ou não das mais diversas situações em que há limitações ao direito fundamental à ação.

Sobretudo aos juízes é fundamental a compreensão desse princípio. Antes de aplicar acriticamente os "rigores da lei", desde a primeira instância até os mais altos tribunais, deve-se fazer uma análise tópica, empírica-dialética do caso concreto, buscando, com base na proporcionalidade, a máxima efetivação dos princípios consagrados na Constituição, nunca temendo decidir contra legem, mas pro pricipium.

Deve, assim, o julgador, como corolário lógico de seu nobre mister, aplicar, sempre que se confrontar com uma situação em que se necessite preservar direitos fundamentais, o princípio da proporcionalidade. Se a lei, por acaso, não está em consonância com o princípio, não deve o magistrado temer em relegar a lei a um segundo plano e concretizar o preceito constitucional em jogo. A função jurisdicional, portanto, só terá sentido se comprometida com os postulados constitucionais; do contrário, melhor não a ter.

E sempre deve estar presente na atividade diária do profissional do Direito o princípio da proporcionalidade. Afinal, de nada valem apelos doutrinários sem a devida e concreta acolhida da teoria pelos verdadeiros operadores das normas jurídicas.

\section{OMISSÃO DE SOCORRO X CONSTRANGIMENTO ILEGAL}

Nem todas as condutas consideradas ilícitas pelos demais ordenamentos (civil, administrativo, tributário) que lesam direitos podem ser consideradas criminosas, pois o Direito Penal somente tipifica as condutas que violam ou expōem a perigo bens jurídicos de elevado valor social, como a vida e a integridade física. Por isso, é correto afirmar que o Direito Penal é composto do mínimo ético necessário à convivência humana, podendo ser definido como um conjunto de normas jurídicas que tem por objeto a determinação de infrações de natureza penal e suas sanções correspondentes.

Primeiramente, necessário elucidar e analisar o conceito da omissão de socorro prevista no art. 135 do Código Penal: 
Art. 135. Deixar de prestar assistência, quando possível fazê-lo sem risco pessoal, a criança abandonada ou extraviada, ou a pessoa inválida ou ferida, ao desamparo ou em grave iminente perigo; ou não pedir, nesses casos, o socorro da autoridade pública:

Pena - detenção, de um a seis meses, ou multa.

Parágrafo único. A pena é aumentada de metade, se da omissão resulta lesão corporal de natureza grave, e triplicada, se resulta a morte.

O sujeito ativo deste delito é aquele que tem o dever de prestar assistência (no caso da transfusão de sangue, é o médico).

Em relação à não realização da transfusão de sangue, em respeito à autodeterminação do paciente, "há quem sustente a possibilidade de prevalência da vontade manifesta pela recusa em submeter-se à transfusão, inclusive com questionamento da constitucionalidade do art. 146, $\S 3^{\circ}$, I e II, do Código Penal"(38). No caso em tese, fica uma dúvida para o médico que realiza a transfusão de sangue, se incorre nas penas do art. 146.

De acordo com Aldir Guedes Soriano e Carlos Ernani Constantino, a intervenção médica realizada sem o consentimento do paciente ou seu representante legal é justificável em face do iminente perigo de vida, conduta essa que inclusive está chancelada pelo Código de Ética Médica, em seu art. $46^{(39)}$.

Sobre o assunto, interessa tratar do inciso primeiro, pois segundo consta, a intervenção médica ou cirúrgica, sem o consentimento do paciente ou de seu representante legal, se justifica por iminente perigo de vida. Assim sendo, mesmo sem o consentimento do paciente ou de seu representante legal o médico poderia atuar sem que incorresse em infração penal alguma. Se assim ainda não fosse, ou seja, se não existisse previsão legal como a citada, esse ato do médico adequar-se-ia às elementares do artigo mencionado (art. 146) e sua conduta seria abraçada pela excludente de ilicitude do estado de necessidade, tendo em vista que da leitura do art. 24 do Código Penal extrai-se que age em estado de necessidade quem pratica o fato para salvar de perigo atual, que não provocou por sua vontade e, cujo sacrifício, nas circunstâncias, não era razoável exigir-se.

\section{CONCLUSÃO}

Foi analisado no presente artigo a responsabilidade penal do médico nos casos de transfusão de sangue em pacientes menores de idade perten-

(38) MORAES, Rodrigo Innaco de; PIRES, Rodrigo Esteves dos Santos. Transfusão de sangue em pacientes testemunhas de Jeová: religião, ética e discurso jurídico-penal. Rev. Jur. UNIJUS, UberabaMG, v. 8, n. 8, p. 93, maio 2005.

(39) Art. 46 CEM: É vedado ao médico: efetuar qualquer procedimento médico sem o esclarecimento e o consentimento prévio do paciente ou de seu responsável legal, salvo em iminente perigo de vida. 
centes à seita religiosa Testemunha de Jeová, em choque hipovolêmico por perda sangüínea, ou melhor, em iminente perigo de vida onde foram discutidas as questōes religiosa, jurídica e médica.

Em relação à questão religiosa, os adeptos desta religião, baseados na interpretação bíblica, não admitem que qualquer pessoa de sua família se submeta à transfusão de sangue, mesmo em iminente perigo de vida.

$\mathrm{Na}$ questão jurídica foram analisados os aspectos constitucionais do art. $5^{\circ}$, caput, II e VI em que fica bem claro que a todos é assegurada a inviolabilidade de fazer ou deixar de fazer alguma coisa, e a liberdade de crença.

Foram estudados ainda os dispositivos 145 e 146 do Código Penal que tratam da não prestação de assistência quando possível fazê-lo, e do constrangimento mediante violência ou grave ameaça por parte do médico atendente.

Na parte médica, foram abordados os arts. 46, 56 e 57 do Código de Ética Médica que vedam ao médico efetuar qualquer procedimento sem o esclarecimento e o consentimento prévio do paciente ou de seu responsável legal; desrespeitar o direito do paciente de decidir livremente sobre a execução de práticas terapêuticas e não utilizar todos os meios disponíveis de diagnóstico e tratamento a seu alcance em favor do paciente.

Quando o médico é impedido pela família de realizar transfusão de sangue, entra em conflito consigo mesmo, pois a sua formação direciona-o a salvar vidas e, ao proceder a transfusão, contra a vontade do paciente, estará sujeito à responsabilização civil e penal, por intervir no corpo do paciente, sem o indispensável consentimento.

Em caso de recusa de transfusão de sangue, o médico deve obedecer ao seu Código de Ética Médica, observando que, se não for o caso de iminente risco de vida, este deverá respeitar a vontade de seu paciente ou responsável legal, buscando formas alternativas de tratamento. Se o paciente estiver em iminente risco de vida, o médico deverá praticar a transfusão de sangue, independentemente do consentimento do paciente ou responsável legal, buscando para isso, intervenção do Ministério Público e, se necessário, reforço policial.

\section{REFERENCIAS}

ALMEIDA, Maria Christina de. Uma reflexão sobre o significado do princípio da proporcionalidade para os direitos fundamentais. Disponível em: <http// www.ufpr.br/direito/art/mariac2.htm> Acesso em: 8.out.2005.

BASTOS, Celso Ribeiro. Curso de direito constitucional. 19. ed. São Paulo: Saraiva, 1998. 
BOSSO, Valderez; MENDES, Regiane A. Questōes constitucionais e legais referentes a tratamento médico sem transfusão de sangue. Disponível em: <http//www.oabjundiai.org.br/artigos_19_05_2005.htm> Acesso em 19.maio.2005.

BRAGA, Valeschka e Silva. Princípios da proporcionalidade \& da razoabilidade. Curitiba: Juruá, 2004.

CHERNICCHIARO, Luiz Vicente. Transfusão de sangue. Revista Jurídica, $n$. 262, ago.1999.

DORSA, Paschoal José. O direito à vida e à liberdade de crença. Testemunhas de Jeová. Transfusão de sangue. Assinatura de termo de responsabilidade e autorização. Recusa. Procedimento Médico e Administrativo, em face da Constituição. Revista dos Tribunais, São Paulo, v. 84, n. 714, 1995.

FIALHO, Carla Cabogrosso. Transfusão de sangue e Testemunhas de Jeová - autonomia x Ética Médica. Revista do Instituto de Pesquisa e Estudos, Bauru, v. 36, 2003.

FINUCAIVE, M. L.; SLOVIC, P.; MERTIZ, C. K. Public perception of the risk of blood transfusion. United States. Transfusion, v. 40, aug.2000.

FRANÇA, Genival Veloso. Comentários ao Código de Ética Médica. 3. ed. Rio de Janeiro: Guanabara Koogan, 2000.

GILLON, Rassan. Refusal of potentially life-saving blood transfusions by Jehovah's witnesses: should doctor explain that not all JWs thinks it's religiously required? Journal of Medical Ethics, v. 26, 2000.

LEME, Ana Carolina Reis Paes. Transfusão de sangue em testemunhas de Jeová: a colisão de direitos fundamentais. Disponivel em: <http//jus2.com.br/ doutrina/texto.asp?id=6545.> Acesso em: 8.out.2005.

LIMA, George Marmelstein. A hierarquia entre princípios e a colisão de normas constitucionais. Disponivel em: <http//www.ambito-juridico.com.br/aj/dt>. Acesso em: 8.out.2005.

MENEZES, Aldo. As testemunhas de Jeová e a Bíblia. São Paulo: Vida, 2003.

MONTE, Fernando Q. A ética na pratica médica. Disponível em: <http// www.portalmedico.org.br/revista/bio10v2/artigo2.htm >. Acesso em: 10.out.2005.

MORAES, Alexandre de. Direito constitucional. 12. ed. São Paulo: Atlas, 2002.

MORAES, Rodrigo Innaco de; PIRES, Rodrigo Esteves dos Santos. Transfusão de sangue em pacientes testemunhas de Jeová: religião, ética e discurso jurídico-penal. Rev. Jur. UNIJUS, Uberaba- MG, v. 8, n. 8, maio 2005.

NERY, Daniel Christianini. Breves comentários sobre os direitos fundamentais. Disponível em: <http//www.revistaautor.com.br/artigos/2002/w14/ DNN_14shtml> Acesso em: 7.out.2005. 
ORLANDO, José Maria da Costa. Alguns aspectos ético-legais da prática do intensivismo. Disponível em: <http//www.sopati.com.br/aspectoseticos.htm> Acesso em: 4.jun.2005.

ROLIM, Luciano Sampaio Gomes. Colisão de direitos fundamentais e princípio da proporcionalidade. Disponível em: <http//www.jus2.uol.com.br/doutrina/ texto.asp?id=2855>. Acesso em: 8.ago.2005.

SILVA, José Afonso da. Curso de direito constitucional positivo. 15. ed. São Paulo: Malheiros Ed., 1998.

VALE, Nilton Bezerra do; TSA, José Delfino. As nove premissas anestesiológicas da Bíblia. Revista Brasileira de Anestesiologia, v. 53, n. 1, 2003.

VIEIRA, Tereza Rodrigues. Reflexões bioéticas na recusa de transfusão de sangue em testemunhas de Jeová. Revista Consulex, Brasília, ano 8, n. 182, 15.ago.2004.

WADE, Paul. Treatment of patients who are jehovas witnesses. Journal of Medical Ethics, v. 27, 2001. 